\title{
A Method for Calibration of the Local Magnitude Scale Based on Relative Spectral Amplitudes, and Application to the San Juan Bautista, California, Area
}

\author{
by Jessica C. Hawthorne, Jean-Paul Ampuero, and Mark Simons
}

\begin{abstract}
We develop and use a spectral empirical Green's function approach to estimate the relative source amplitudes of earthquakes near San Juan Bautista, California. We isolate the source amplitudes from path effects by comparing the recorded spectra of pairs of events with similar location and focal mechanism, without computing the path effect. With this method, we estimate the relative moments of $1600 M 1.5-4$ local earthquakes, and we use these moments to recalibrate the duration magnitude scale in this region. The estimated moments of these small earthquakes increase with catalog magnitude $M_{\mathrm{D}}$ roughly proportionally to $10^{1.1 M_{\mathrm{D}}}$, slightly more slowly than a moment-magnitude scaling of $10^{1.5 M_{\mathrm{w}}}$. This more accurate magnitude scaling can be used in analyses of the local earthquakes, such as comparisons between the seismic moments and geodetic observations.
\end{abstract}

Electronic Supplement: Additional description and figures showing estimated source amplitudes obtained with different parameters, and observed amplitudes of some earthquakes with large misfits.

Introduction: Background on Magnitude Estimates

Earthquake moments are required for a variety of investigations. They are used when examining earthquake statistics, as in $b$-value studies (e.g., Wiemer et al., 2002; Wyss et al., 2004; Ghosh et al., 2008), when interpreting earthquake rates, as in studies of repeating earthquakes (e.g., Nadeau and Johnson, 1998; Templeton et al., 2008; Werner and Sornette, 2008; Taira et al., 2014), and when comparing geodetic and seismic observations, as in studies of postseismic slip (e.g., Bell et al., 2012; Fattahi et al., 2015; Hawthorne et al., 2016). Here, we use an empirical Green's function approach to estimate the relative moments of about 1600 earthquakes near San Juan Bautista, California. Located at the northern end of the creeping section of the San Andreas fault (see Fig. 1), the San Juan Bautista area is of particular interest because many of the earthquakes are observed with nearby borehole strainmeters. The strain data present an opportunity to compare the seismic moments with postseismic moments estimated from geodesy (Hawthorne et al., 2016).

Moment estimates already exist for this area. Magnitudes are routinely estimated and cataloged by the Northern California Seismic Network (NCSN, see Data and Resources) and the Berkeley Seismological Laboratory. Local earthquake magnitudes are often estimated from the amplitudes or durations of signals recorded at regional stations, with adjust- ments for earthquake-station separations and site effects. In the NCSN catalog, magnitudes smaller than $M 4$ are usually duration magnitudes. These magnitudes are computed from the length of time the earthquake signal stays above the noise (e.g., Lee et al., 1972; Herrmann, 1975; Bakun, 1984a,b; Michaelson, 1990; Eaton, 1992).

Magnitude scales are calibrated so that magnitudes are logarithmic in the seismic moment $M_{0}$ :

$$
M_{0}=\alpha 10^{\beta M},
$$

in which $\alpha$ and $\beta$ are constants. $\alpha$ determines the absolute moment, and $\beta$ measures the change in seismic moment per unit magnitude. In an ideal scenario, the catalog magnitude $M$ is equal to a moment magnitude $M_{\mathrm{w}}$, making $\alpha=1.26 \times$ $10^{9} \mathrm{~N} \cdot \mathrm{m}$ and $\beta=1.5$ (Hanks and Kanamori, 1979).

The NCSN duration magnitude $\left(M_{\mathrm{D}}\right)$ scale was calibrated in the early 1990s by Michaelson (1990) and Eaton (1992). Parameters were chosen to match the amplitude-based local magnitude $\left(M_{\mathrm{L}}\right)$ scale. The $M_{\mathrm{L}}$ scale had been previously compared with moment magnitudes obtained from spectral modeling. It was found that $M_{0} \sim 10^{1.0 \text { to } 1.3 M_{\mathrm{L}}}$ for small earthquakes $\left(M_{\mathrm{L}} \lesssim 4\right)$, and $M_{0} \sim 10^{1.3}$ to $1.5 M_{\mathrm{L}}$ for larger events $\left(M_{\mathrm{L}} \gtrsim 4\right)$ (Bakun and Lindh, 1977; Archuleta et al., 1982; Bakun, 1984b; Fletcher et al., 1984). Both the local $M_{\mathrm{L}}$ and 

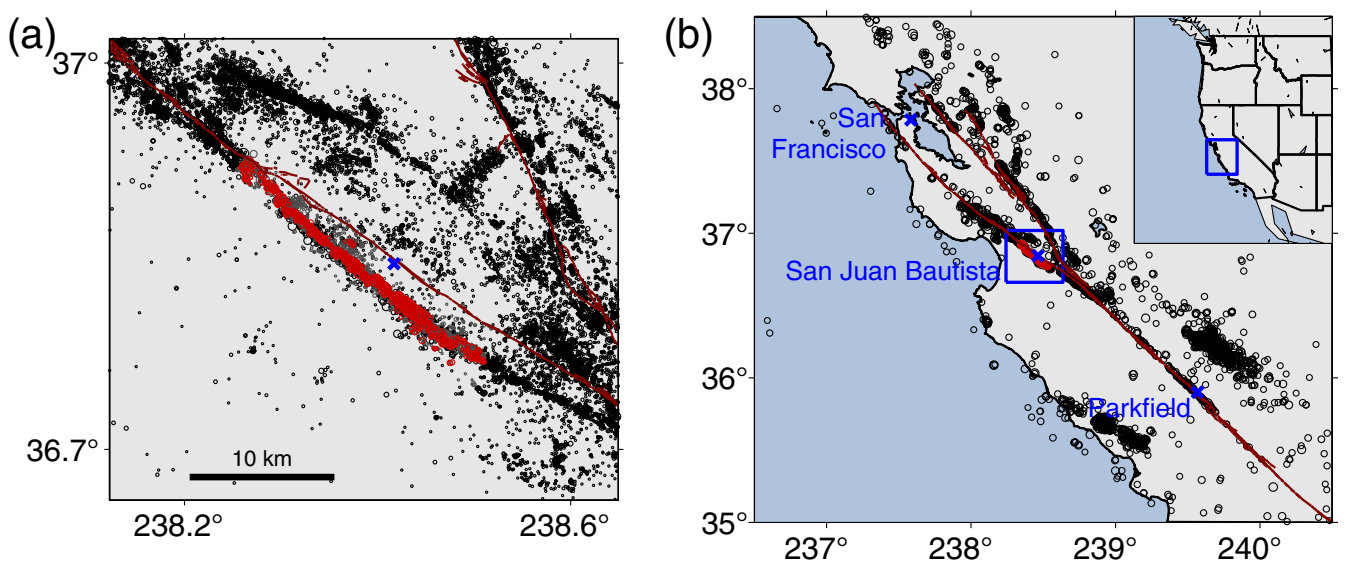

Figure 1. Location of the analyzed earthquakes. The region of interest is near San Juan Bautista, at the northern end of the creeping section of the San Andreas fault. Lines show the San Andreas, Calaveras, and Hayward faults (from the U.S. Geological Survey and Central Geological Survey quaternary fault and fold database, see Data and Resources). Bright circles indicate the earthquakes with re-estimated moments, gray circles indicate earthquakes within the region of interest that are not used in the calibration, and black circles indicate regional $M>3$ earthquakes from the Northern California Earthquake Data Center catalog. Double difference locations from Waldhauser (2009) are used where available. The color version of this figure is available only in the electronic edition.

duration $M_{\mathrm{D}}$ magnitude scales have evolved as regional stations were added and removed, but efforts have been made to retain temporal consistency (Uhrhammer et al., 1996, 2011).

Catalog magnitude scales like the NCSN duration magnitude $\left(M_{\mathrm{D}}\right)$ scale are designed to function for decades of earthquakes with a range of magnitudes occurring over large regions. It is thus unsurprising that the scaling between moment and catalog magnitude can vary somewhat with location and with the magnitude range considered (e.g., Bindi et al., 2005; Castello et al., 2007; Edwards et al., 2010; Gasperini et al., 2013). For instance, Wyss et al. (2004) examined small earthquake moments near Parkfield, California, and found a scaling parameter $\beta$ of 1.6 for duration magnitudes, larger than the $\beta$ of 1.0-1.3 previously obtained for small events on the local magnitude $\left(M_{\mathrm{L}}\right)$ scale (Bakun and Lindh, 1977; Archuleta et al., 1982; Bakun, 1984b, Fletcher et al., 1984). Abercrombie (1996) found that $\beta \approx 1.0$ near Cajon Pass when comparing with the Southern California Seismic Network magnitudes, and Ben-Zion and Zhu (2002) noted that $\beta$ increased to 1.3 for $M_{\mathrm{L}}>3.5$ earthquakes. Ross et al. (2016) estimated that $\beta \approx 1.1$ from around 8000 earthquakes around the San Jacinto fault zone. On a larger scale, Shearer et al. (2006) estimated that $\beta \approx 1.0$ for $M \lesssim 3$ earthquakes in southern California. The small scaling factor $\beta<1.5$ often observed for local magnitudes of small earthquakes may arise because the seismic waves at the recording frequencies depend on the earthquake source duration (Hanks and Boore, 1984; Deichmann, 2006; Edwards et al., 2010; Bethmann et al., 2011), because earthquake characteristics change with magnitude (Ben-Zion and Zhu, 2002), or because attenuation is larger at the higher dominant frequencies of smaller earthquakes (Deichmann, 2006; Edwards et al., 2010; Bethmann et al., 2011).

Uncertainty in the corrections for path and site effects generate a large part of the error in earthquake moment estimates. A variety of techniques have been developed to avoid these problems and isolate the relative moments of earthquakes. Schaff and Richards (2014) and Cleveland and Ammon (2015) estimated moments by comparing the amplitudes and cross correlations of earthquake pairs. Rubinstein and Ellsworth (2010) identified coherent signals in repeating earthquake records and compared their amplitudes. Empirical Green's function approaches are also common. With these techniques, one compares the amplitudes of clusters of earthquakes or solves for common path effects (e.g., Mueller, 1985; Mori and Frankel, 1990; Velasco et al., 1994; Hough, 1997; Prieto et al., 2004; Imanishi and Ellsworth, 2006; Shearer et al., 2006; Baltay et al., 2010; Kwiatek et al., 2011; Uchide et al., 2014).

Here, we use an empirical Green's function approach to estimate the relative moments of $1600 M<4$ earthquakes near San Juan Bautista, California. We isolate earthquake source amplitudes from the path and site effects by comparing the amplitudes of nearby earthquakes recorded at common stations. Our approach differs from other techniques on a similar scale in that it does not require us to solve for the path and site effects. We use the estimated source amplitudes to recalibrate the duration magnitude scale for the $20 \mathrm{~km}$ region of interest.

We first describe our approach to estimating earthquake source amplitudes and obtain uncertainties on those amplitudes. Then we convert the amplitudes to moments and recalibrate the magnitude scale. Finally, we illustrate how our method contributes to earthquake scaling studies.

\section{Obtaining Relative Source Amplitudes}

We estimate the relative moments of about 1600 local earthquakes from the low-frequency $(2-4 \mathrm{~Hz}) P$-wave spectra. The $2-4 \mathrm{~Hz}$ frequency range is smaller than the corner frequencies of most of the earthquakes of interest, but it 
(a)
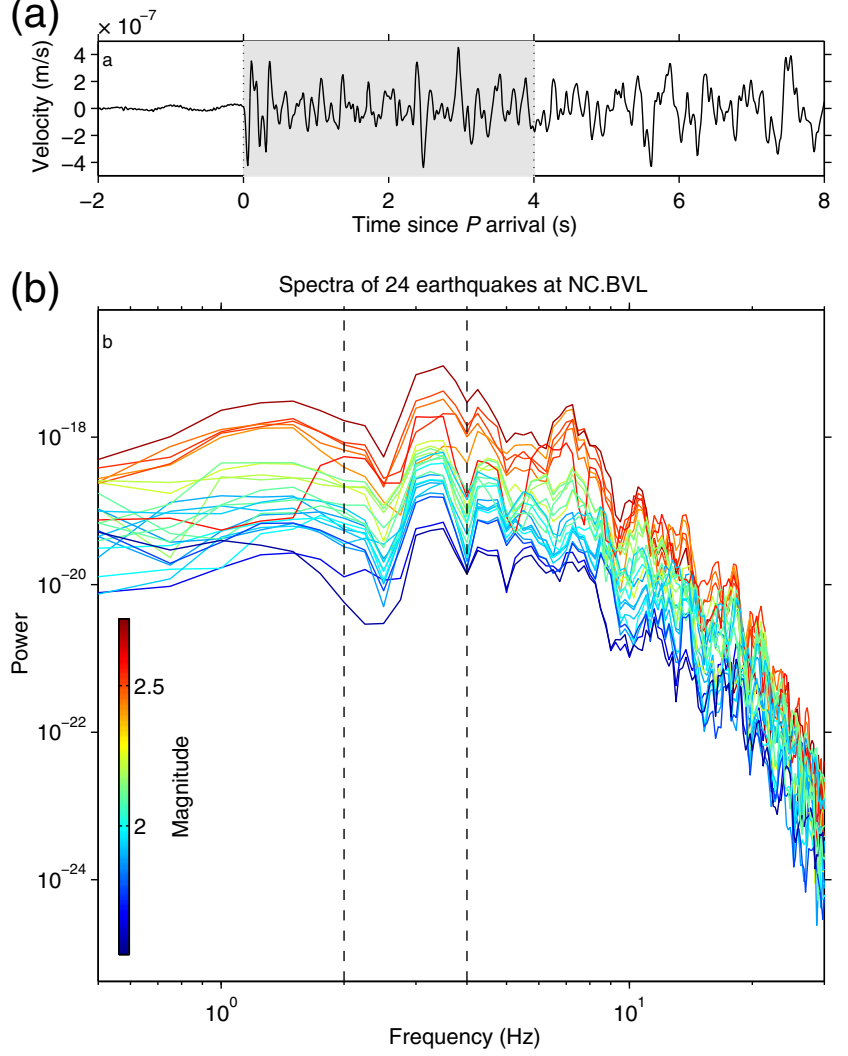

Figure 2. (a) Vertical ground velocity at Northern California Seismic Network (NCSN) station BVL due to an $M 2.2$ earthquake $41 \mathrm{~km}$ away, on 22 January 1995 00:46:04. The gray region and vertical dotted lines indicate the time period used to compute the spectra. (b) The displacement spectra from this and 23 other earthquakes recorded at station BVL. All of the earthquakes are within $0.5 \mathrm{~km}$ of each other. The amplitudes are larger for larger magnitude earthquakes. Vertical dashed lines indicate the frequency range used to determine the relative amplitudes. The color version of this figure is available only in the electronic edition.

avoids frequencies $<1 \mathrm{~Hz}$ where the seismometers lose sensitivity. The data are vertical-component seismograms from NCSN network stations. We extract the first $4 \mathrm{~s}$ of the $P$-wave arrivals at stations with signal-to-noise ratio (SNR) larger than 3 and compute the displacement spectra (for details, see the Appendix). One example of the velocity records is shown in Figure 2a, and the spectra of 24 earthquakes recorded at station BVL are shown in Figure 2b. The amplitudes fall off with increasing frequency because of source effects and attenuation.

We are interested in the low-frequency amplitudes, which are larger for larger earthquakes, as expected. Amplitudes at frequencies smaller than the corner frequencies should scale linearly with the seismic moment (e.g., Aki and Richards, 2002).

The observed amplitudes also depend on the path traveled by the seismic waves. The amplitude at frequency $\omega$ may be written as the product of the source amplitude and the path amplitude. If we let $S_{i}(\omega)$ be the amplitude of the source time function of earthquake $i$, and let $G_{i k}(\omega)$ be the amplitude of the Green's function for propagation from earthquake $i$ to station $k$, the observed signal is

$$
D_{i k}(\omega)=S_{i}(\omega) G_{i k}(\omega) .
$$

When we take the logarithm of each term, $d_{i k}=\log _{10}\left(D_{i k}\right)$, $s_{i}=\log _{10}\left(S_{i}\right)$, and $g_{i k}=\log _{10}\left(G_{i k}\right)$, equation (2) becomes

$$
d_{i k}=s_{i}+g_{i k}
$$

(Aki and Richards, 2002).

We wish to solve for the earthquake source amplitudes $s_{i}$ in the 2-4 Hz range. Because we do not know the path effects $g_{i k}$, we use a spectral empirical Green's function approach (e.g., Hough, 1997; Ide et al., 2003; Imanishi et al., 2004; Imanishi and Ellsworth, 2006; Shearer et al., 2006; Baltay et al., 2010; Kwiatek et al., 2011; Harrington et al., 2015). If we consider a pair of earthquakes $i$ and $j$ with similar paths and focal mechanisms, we may expect similar Green's functions, and thus we can eliminate the Green's function by dividing the spectra. Subtracting the log spectra in equation (3) gives

$$
s_{i}-s_{j}+\left(g_{i k}-g_{j k}\right)=d_{i k}-d_{j k} .
$$

Here we also assumed little or similar rupture directivity. Most of the small earthquakes considered here are likely to show little directivity in the $2-4 \mathrm{~Hz}$ band, as their corner frequencies are usually higher than $4 \mathrm{~Hz}$.

Many well-recorded and closely spaced earthquakes occur along the San Andreas fault near San Juan Bautista. The events are located on a well-defined fault plane, and we expect most events to occur on this plane. Out of the 34 reviewed focal mechanisms in the NCSN catalog for our study area, 28 are within $30^{\circ}$ of right-lateral slip on the seismicitydefined fault plane (see (E) Fig. S1, available in the electronic supplement to this article). We consider pairs of earthquakes that occur within $2 \mathrm{~km}$ of each other, are recorded at the same station, and have travel times that differ by less than $0.2 \mathrm{~s}$. We use data from 300 stations to obtain 40,000 amplitudes of 2700 earthquakes that occurred between 1988 and 2014 in the $20 \mathrm{~km}$ region illustrated in Figure 1. These measurements provide about 1.4 million $\log$ amplitude ratios $d_{i k}-d_{j k}$. We discard some of the data in the interest of robustness, as described in the (E) electronic supplement. In the final inversion, there are 1600 earthquakes with 1 million spectral ratios from 200 stations. We use the observed ratios $d_{i k}-d_{j k}$ to construct the system of equations (4), with unknown source amplitudes $s_{i}$, as was done for corner-frequency estimation by, for example, Ide et al. (2003, 2004), Imanishi et al. (2004), Oye et al. (2005), Imanishi and Ellsworth (2006), Kwiatek et al. (2011), Harrington et al. (2015), and Kwiatek et al. (2015).

We will solve for the source amplitudes $s_{i}$, but first we address possible biases in our approach. One potential bias comes from overweighting individual observations that are 




Figure 3. Estimated source amplitudes versus catalog magnitude. The catalog magnitudes are $M_{\mathrm{D}}$ estimates (circles and crosses), $M_{\mathrm{w}}$ estimates (triangles and stars), and $M_{\mathrm{L}}$ estimates (squares and plus signs). The slope of the amplitude-magnitude curve is a rough estimate of $\beta$ in the assumed scaling $M_{0}=\alpha 10^{\beta M}$. The best-fitting slope for the earthquakes with $M_{\mathrm{D}}$ magnitudes is between 1.0 and 1.05. The best-fitting slope for the moments of the $M_{\mathrm{D}}$ earthquakes (plotted in Fig. 7) is $\sim 1.1$, as indicated by the solid line. If the catalog magnitude were a moment magnitude, one would expect a slope $\beta$ of 1.5 (dashed line). The color version of this figure is available only in the electronic edition.

part of many earthquake pairs. A second comes from the azimuthal distribution of stations. There are more stations to the northwest and southeast, along the fault, than to the northeast and southwest. We consider these potential error sources in the (E) electronic supplement but find that they do not significantly affect the magnitude scaling we obtain. Nevertheless, in the (E) electronic supplement we determine a preferred weighting $c_{i j k}$ for each equation (4) that makes our solution less sensitive to the nonuniform distribution of observations. The weights are based on the number and azimuthal distribution of the observations available for each earthquake. The new equations are

$$
c_{i j k}\left(s_{i}-s_{j}\right)=c_{i j k}\left(d_{i k}-d_{j k}\right) .
$$

To avoid overweighting large misfits in the solution of equation (5), we use a least-squares misfit when the predicted log (base 10) ratio differs from the observed log ratio by less than 0.2 and an absolute value misfit for larger differences.

In equation (5), the earthquakes' relative source amplitudes are overdetermined, because they are constrained by multiple observed ratios. However, the absolute source amplitude, that averaged over all events, is entirely unconstrained. To solve the equations in practice, then, we choose a single source $s_{i}$ with many observed links $\left(d_{i k}-d_{j k}\right)$ to other events $j$ and require that $s_{i}=0$. We choose to fix a single source amplitude rather than the average source amplitude because we find this constraint less sensitive to the regularization weighting. Fixing the average source amplitude to zero can encourage all the amplitudes $s_{i}$ to tend to zero if the regularization is weighted too strongly. In contrast, fixing the amplitude of a single source places no constraint on the amplitude ratios $s_{i}-s_{j}$, so we can be assured that the relative amplitudes $s_{i}-s_{j}$ are constrained by the data, not the regularization. We tested our inversions with various sources $s_{i}$ chosen as the zero reference and obtain identical relative source amplitudes. These source amplitudes are plotted against catalog magnitude in Figure 3.

\section{Bootstrap Error Estimates}

To obtain rough uncertainties on the source amplitudes, we redo our inversions with various subsets of the data. To select appropriate subsets, we note that the dominant errors in our approach do not result from poor SNR in individual seismograms but from poor assumptions about those seismograms.

For instance, we assume that the path effect is the same for closely spaced earthquakes, but the path effects may vary if the local velocity structure is complicated. The amplitude might also vary as the result of rupture directivity. For $M \gtrsim 3$ earthquakes with low corner frequencies, rupture directivity could enhance or reduce the apparent source amplitude in the 2-4 Hz band. Finally, the observed seismogram amplitudes could vary for closely spaced earthquakes if the events have different focal mechanisms. The focal mechanism effects may be especially pronounced near the nodal planes. So as a first assessment of the uncertainty, we redo our inversions without observations within $15^{\circ}$ of the expected nodal planes. As discussed in the (E) electronic supplement and shown in (E) Figure S3, the obtained seismic amplitudes do not change significantly.

To assess uncertainties more generally, we note that focal mechanism, directivity, and velocity structure variations often give rise to seismic amplitudes that vary with azimuth. We therefore choose to divide and resample our data by azimuth. We split the observations into eight groups based on their earthquake-station orientation: $0^{\circ}-45^{\circ}, 45^{\circ}-90^{\circ}, 90^{\circ}-135^{\circ}$, and so on. For each of 100 bootstrap inversions, we pick six of these eight groups, with replacement, and solve equation (5) using the same observation weighting described in the $(\mathbb{E})$ electronic supplement. Choosing six rather than eight of the azimuthal groups may cause us to overestimate the uncertainty by about $15 \%$. However, the lower number of groups can help reduce any bias in the bootstrapping that results from the small number of bootstrap samples or from outliers in the observed amplitude ratios (e.g., Chernick, 2007).

From the 100 bootstrap estimates, we compute a $90 \%$ uncertainty for each earthquake amplitude. Figure $4 a$ shows the distribution of $90 \%$ uncertainty estimates, computed relative to the median amplitude. The median $90 \%$ uncertainty is 0.12 (a factor of 1.3), and $90 \%$ of the uncertainties are smaller 

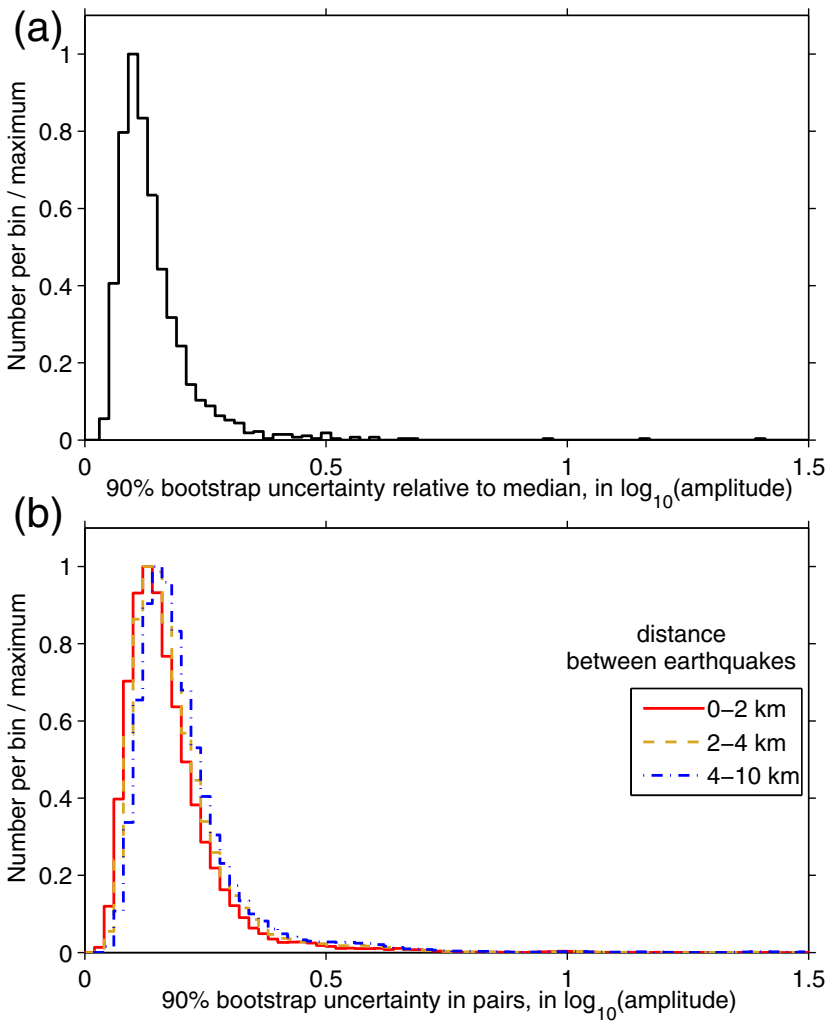

Figure 4. Distribution of source amplitude uncertainties obtained from bootstrapping. (a) $90 \%$ uncertainties in individual source amplitudes, relative to the median. (b) $90 \%$ uncertainties in the amplitude ratio of individual earthquake pairs. The three distributions are for various distance ranges between the two earthquakes. The source amplitude ratios are better constrained when the earthquakes are closer together, presumably because the amplitude ratios of more closely spaced earthquakes are more directly constrained by the data. The color version of this figure is available only in the electronic edition.

than 0.22 (a factor of 1.7). Figure $4 \mathrm{~b}$ shows the distribution of $90 \%$ uncertainties in the source amplitude ratios of various earthquake pairs. The solid, dashed, and dashed-dotted curves show the errors for earthquake pairs in three distance ranges: 0-2 km, 2-4 km, and 4-10 km. The amplitude ratios of nearby earthquakes are better constrained than the amplitude ratios of more widely spaced earthquakes, presumably because the source amplitude ratios of more widely spaced earthquakes must be obtained indirectly, through a series of earthquake pairs. The data in equation (5) include the observed amplitude ratios only of earthquakes less than $2 \mathrm{~km}$ apart.

\section{Corrections for High-Frequency Fall-Off}

The source amplitudes shown in Figure 3 are estimated at frequencies of $2-4 \mathrm{~Hz}$, or periods of $0.25-0.5 \mathrm{~s}$. As noted earlier, this frequency range is a compromise between the data sensitivity and the corner frequencies of the earthquakes. Most of the earthquakes have rupture durations much shorter than $0.25 \mathrm{~s}$, so most $2-4 \mathrm{~Hz}$ amplitudes are close to the low-frequency limit and proportional to moment. For the larger earth- quakes with lower corner frequencies, we must recognize that earthquake source spectra generally decrease with increasing frequency. In one observationally acceptable and physically reasonable model, the displacement spectra follow

$$
S(\omega)=\frac{S(0)}{1+\left(\omega / \omega_{0}\right)^{2}}
$$

(e.g., Brune, 1970; Abercrombie, 1995; Hough, 1997; Madariaga, 2007). Here, $S(0)$ is the low-frequency amplitude, which is proportional to moment, $\omega$ is frequency, and $\omega_{0}$ is the corner frequency.

For earthquakes smaller than about $M 3$, the corner frequency $\omega_{0}$ is larger than the $2-4 \mathrm{~Hz}$ frequencies examined here, so $S(\omega) \approx S(0)$. For larger earthquakes, we must multiply the observed amplitudes by $1+\left(\omega / \omega_{0}\right)^{2}$ to obtain a value proportional to moment. We compute the average correction factor in the $2-4 \mathrm{~Hz}$ range, taking the logarithm before averaging because our amplitude estimates are also logarithms: $s_{i}=\log _{10}(S(\omega))$.

To compute the correction factor, we need the corner frequencies $\omega_{0}$. Observed corner frequencies are typically found to decrease with increasing earthquake size, scaling as $M_{0}^{-1 / 3}$ (e.g., Abercrombie, 1995; Prejean and Ellsworth, 2001; Prieto et al., 2004; Allmann and Shearer, 2007; Yamada et al., 2007). We will use this scaling to estimate corner frequencies for our earthquakes from their estimated moments $M_{0}$. Moments are obtained from the relative amplitudes in Figure 3, which are scaled from amplitude to moment through the magnitude calibration in the Scaling to Moment and Catalog Magnitude section. Specifically, we assume that the corner frequencies are related to moments by

$$
\omega_{0}=M_{0}^{-1 / 3} 0.32\left(\frac{16}{7}\right)^{1 / 3} c_{s} \Delta \sigma^{1 / 3}
$$

(Madariaga, 1976), in which $c_{s}$ is the shear wavespeed, which we take to be $3.5 \mathrm{~km} / \mathrm{s}$ and $\Delta \sigma$ is the stress drop, obtained from the physical model of Madariaga (1976). Observed stress drops are usually centered between 0.1 and $20 \mathrm{MPa}$; we assume a magnitude-independent stress drop of $3 \mathrm{MPa}$, within the range of existing observations (e.g., Abercrombie, 1995; Hough, 1997; Prejean and Ellsworth, 2001; Ide et al., 2003; Shearer et al., 2006; Allmann and Shearer, 2007; Kwiatek et al., 2011).

Equation (7) is designed to give an average corner frequency as a function of moment. Corner frequencies of specific earthquakes vary around that average. The standard deviation of estimated stress-drop distributions is typically a factor of $3-10$, implying a factor of 1.25-2 standard deviation in corner frequency (e.g., Imanishi and Ellsworth, 2006; Allmann and Shearer, 2007, 2009; Baltay et al., 2011; Abercrombie, 2014). Such a change in corner frequency can change the correction factor $1+\left(\omega / \omega_{0}\right)^{2}$ by up to a factor of 4 . This unaccountedfor variability contributes to scatter in our moment estimates for larger $(M>3)$ earthquakes, but it should not stop us from finding an appropriate scaling between moment and catalog 


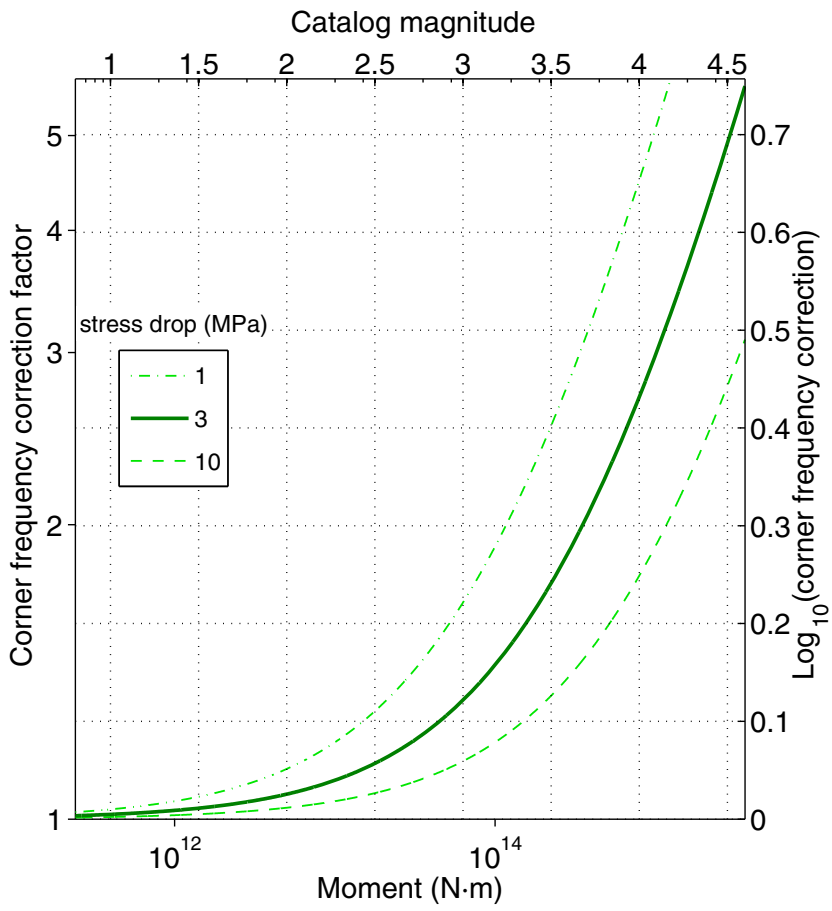

Figure 5. Correction factors as a function of earthquake moment, obtained with equations (6) and (7). The upper $x$ axis shows catalog magnitude, which is related to moment (lower $x$ axis) with the calibration in equation (8). For the assumed $3 \mathrm{MPa}$ stress drops, earthquakes with $M<3.5$ have $\log _{10}$ correction less than 0.25 , a factor of 1.8. The color version of this figure is available only in the electronic edition.

magnitude. In any case, the correction factors are small for most of the earthquakes considered here, as shown in Figure 5. For the assumed $3 \mathrm{MPa}$ stress drops, the correction factors are less than 1.4 when $M<3$ and less than 1.8 when $M<3.5$. The corrections would be larger and more significant for smaller earthquakes if we assumed a smaller stress drop, as illustrated with the dashed curves in Figure 5. However, the source amplitude and magnitude scale linearly for $M<3$ earthquakes in Figure 3, suggesting that there are minimal required cornerfrequency corrections in that magnitude range. Assuming a smaller stress drop would introduce nonlinearity into the moment-magnitude scaling. Although such a nonlinear relationship is possible, we prefer the linear scaling produced by $>3 \mathrm{MPa}$ stress drops as a simpler explanation of the data. For larger earthquakes, with $M>3.5$, the corner-frequency corrections become larger, and our moment estimation method becomes less appropriate. Methods that use waveform modeling are more practical for use in that magnitude range (e.g., Dreger and Helmberger, 1990; Zhu and Helmberger, 1996).

\section{Scaling to Moment and Catalog Magnitude}

Now that we estimated the earthquakes' source amplitudes and developed an approach to account for amplitude decay at high frequencies, we can compare the amplitudes with catalog magnitudes. The log amplitudes shown in
Figure 3 increase roughly linearly with magnitude. They are best fit by a line with slope between 1.0 and 1.05 . This slope is an initial estimate of the scaling factor $\beta$ in equation (1). Slopes of 1.1 and 1.5 are illustrated by the solid and dashed lines in Figure 3. A slope of 1.1 is the $\beta$ that will be obtained in this section after correction for the high-frequency amplitude fall-off. A slope of 1.5 would be expected if the catalog magnitudes $M$ were moment magnitudes $M_{\mathrm{w}}$.

Although we have computed source amplitudes for earthquakes with a variety of magnitude types- $M_{\mathrm{D}}, M_{\mathrm{w}}$, and $M_{\mathrm{L}}$, all reported in the NCSN catalog-we seek to calibrate only the duration magnitude $\left(M_{\mathrm{D}}\right)$ scale, which is the most commonly used magnitude scale for $M<4$ earthquakes in northern California. Thus only earthquakes that have duration magnitudes as their catalog magnitudes are included in the calibration fits.

Although the estimated amplitudes of $M<3$ earthquakes supply the scaling parameter $\beta$ via a simple linear regression, they provide no information about the absolute moment. To convert the amplitudes to moment, we assume that the catalog duration magnitude $M_{\mathrm{D}}$ is equivalent to moment magnitude $M_{\mathrm{w}}$ when $M_{\mathrm{D}}=3.5$. We multiply all the estimated source amplitudes by the same factor, that required to scale the source amplitude of an $M_{\mathrm{D}} 3.5$ earthquake in the linear regression to the moment of an $M_{\mathrm{w}} 3.5$ event. This pinning is approximate. With the assumed pinning at $M_{\mathrm{D}} 3.5$, an $M_{\mathrm{D}} 4$ earthquake has a moment factor of $10^{1.1 \times 0.5}$ larger than an $M_{\mathrm{w}} 3.5$ earthquake, a factor of 1.6 smaller than an $M_{\mathrm{w}} 4$ earthquake. If we had instead assumed that the two magnitude scales crossed at $M_{\mathrm{D}} 4$, all of our estimated moments would be a factor of 1.6 larger. To check that pinning the scale at $M_{\mathrm{D}} 3.5$ is reasonable, we examine the estimated amplitudes of 14 earthquakes that have cataloged moment magnitudes $M_{\mathrm{w}}$. When these amplitudes are converted to moments using the $M_{\mathrm{D}} 3.5$ pinning, with the high-frequency correction described below, 12 of the 14 estimated moments match the cataloged moments to within a factor of 2 (Fig. 6).

The final step in our magnitude calibration is to account for the decrease in seismogram amplitude at higher frequencies, as discussed in the Corrections for High-Frequency Fall-Off section. We compute these corner-frequency corrections and the linear regression for $\beta$ iteratively. First, we perform the linear regression and scale the amplitudes to a first estimate of the earthquake moments, as described above. Then, we use the moment estimates to convert the amplitudes estimated in the $2-4 \mathrm{~Hz}$ band to the amplitudes expected in the low-frequency limit, assuming a $3 \mathrm{MPa}$ stress drop. It is this low-frequency amplitude that should be proportional to moment. We therefore redo the amplitude-magnitude regression with the inferred low-frequency amplitudes. This fit gives a new scaling parameter $\beta$ and a new factor that converts all the amplitudes to moments. We repeat the cornerfrequency corrections and the linear fit until the parameters converge. In all linear fits, we use a least-squares misfit for small misfits from the regression and an absolute value misfit for source amplitudes that differ from the linear trend by 


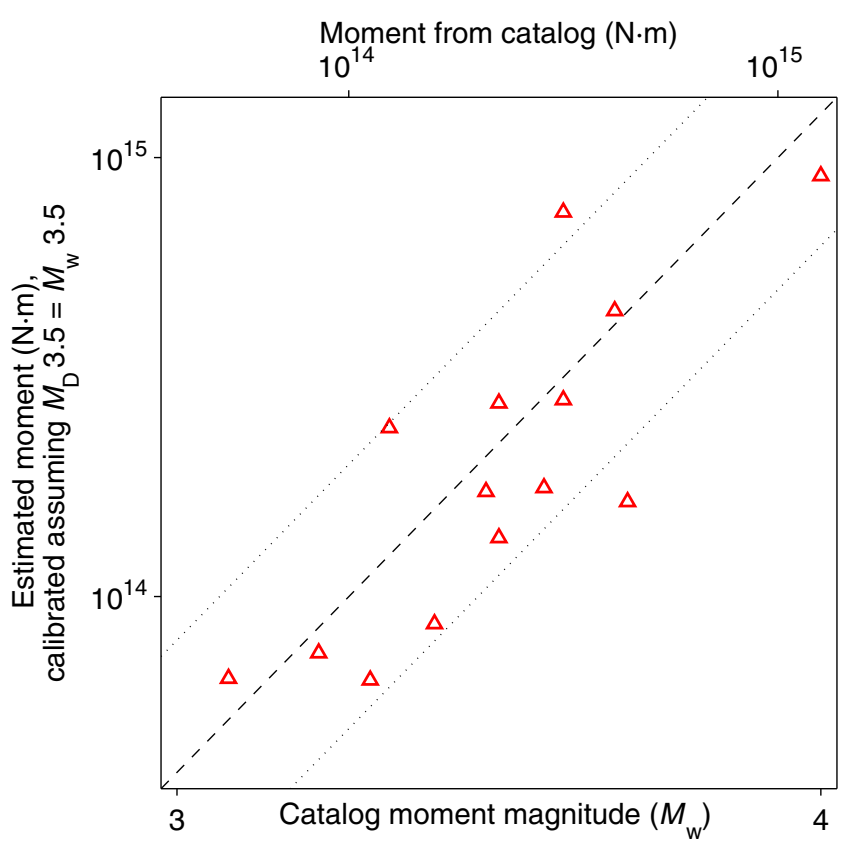

Figure 6. Estimated moments of earthquakes with cataloged $M_{\mathrm{w}}$, against the catalog $M_{\mathrm{w}}$. The plot is an expansion of the $M_{\mathrm{w}}$ values plotted in Figure 7. Estimated moments are obtained from the relative amplitudes by assuming that an $M_{\mathrm{D}} 3.5$ earthquake has the same moment as an $M_{\mathrm{w}} 3.5$ earthquake. Moments are also corrected for the decrease in amplitude above the corner frequencies. The black dashed line indicates a one-to-one scaling, and the dotted lines delineate a factor of two moment difference. The color version of this figure is available only in the electronic edition.

more than 0.2 , so that we do not overweight a handful of outliers.

The final best-fitting slope $\beta$ is 1.12 . To estimate its uncertainty, we redo the fits with our bootstrapped amplitude sets. $90 \%$ of the resulting slopes are between 1.09 and 1.14. Some additional uncertainty comes from the stress drop assumed in the corner-frequency corrections. If we assumed larger stress drops of 10 or $30 \mathrm{MPa}$ instead of $3 \mathrm{MPa}$, we would obtain slopes $\beta$ of 1.07 or 1.05 , respectively. A smaller stress drop of $1 \mathrm{MPa}$ would give a larger slope $\beta$ of 1.18 , but as noted earlier, the linearity of the amplitude-magnitude plot for $M<3$ earthquakes (Fig. 3) suggests that such a small average stress drop is less likely. For simplicity, we approximate the best-fitting slope as 1.1 , which gives moment $M_{0}$ as a function of catalog magnitude $M_{\mathrm{D}}$ via

$$
M_{0}=10^{1.1\left(M_{\mathrm{D}}-3.5\right)} 2.2 \times 10^{14} \mathrm{~N} \cdot \mathrm{m} .
$$

This scaling is illustrated with the solid line in Figure 7. It is plotted along with the corner-frequency-corrected amplitudes, scaled to moment. The moments are similar to the uncorrected amplitudes in Figure 3 except that the largemagnitude amplitudes have been increased slightly. The magnitude of this increase is illustrated with the dasheddotted line in Figure 7; the vertical distance between the solid and dashed-dotted curves is the amplitude of the corner frequency correction on the solid curve.

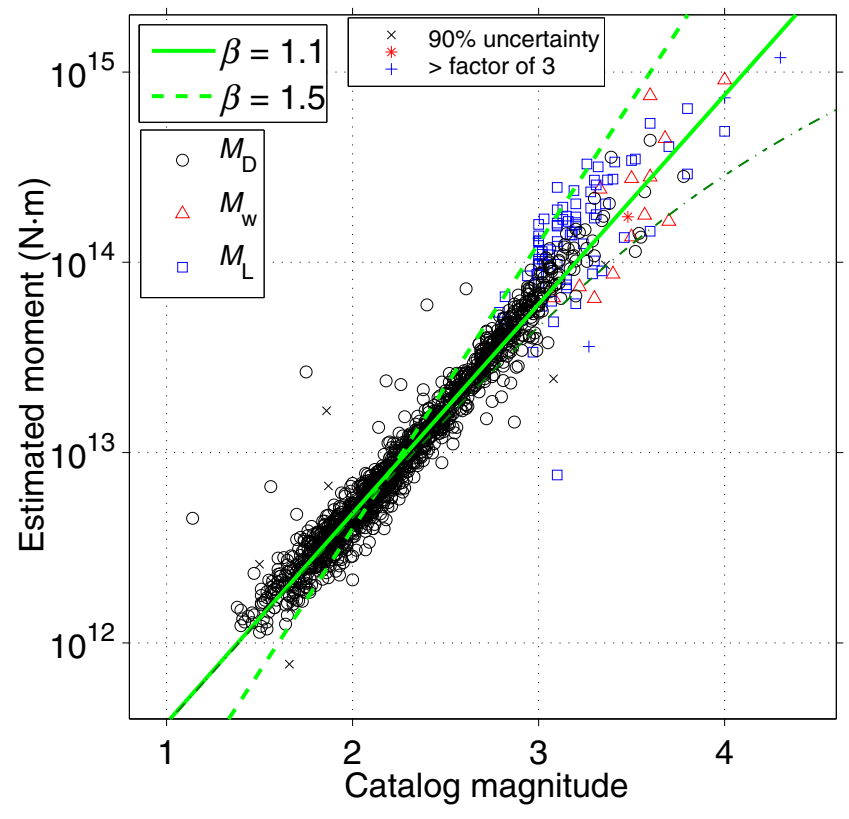

Figure 7. Moments estimated from observed amplitudes versus catalog magnitude. Symbols are as in Figure 3. The slope of this moment-magnitude curve is the value $\beta$ in the assumed scaling $M_{0}=\alpha 10^{\beta M}$. The best-fitting slope is $\sim 1.1$, as indicated by the solid line. If the catalog magnitude were a moment magnitude, one would expect a slope $\beta$ of 1.5 (dashed line). The dashed-dotted curve that closely follows the $\beta=1.1$ line for $M<3$ illustrates the corner frequency correction. The vertical distance between the solid and dashed-dotted curves is the log correction factor for the moment on the solid line. The color version of this figure is available only in the electronic edition.

A magnitude calibration with $\beta=1.1$ is consistent with previous calibrations of the local magnitude scale for small earthquakes (Bakun and Lindh, 1977; Archuleta et al., 1982; Bakun, 1984b, Fletcher et al., 1984). For comparison with this scaling, also plotted in Figure 7 is a line with $\beta=1.5$ (dashed curve), the slope expected for moment magnitudes $M_{\mathrm{w}}$. This slope clearly does not capture the overall trend, but it is closer to matching the amplitudes in the $M>3$ range. The estimated moments increase more quickly with catalog magnitude when the magnitude is larger. This curvature was also seen in earlier comparisons of moment and local (amplitude-based) magnitude, though over a wider magnitude range (Bakun and Lindh, 1977; Archuleta et al., 1982; Bakun, 1984b; Fletcher et al., 1984). For the magnitude range considered here, the curvature is slight, and it may simply imply that our assumed $3 \mathrm{MPa}$ stress is slightly smaller than the actual values. A linear trend for the entire magnitude range matches the data well. $90 \%$ of the log amplitude residuals are smaller than 0.14: a factor of 1.4. There is no spatial trend in the residuals, as discussed in the Appendix.

There are, however, several earthquakes with large difference between the estimated moment and the moment predicted by the calibration. For a few of these, the uncertainty obtained via bootstrapping is also large, and the residual moment is likely noise (crosses, stars, and plus signs in Fig. 7). For 
the remaining nine earthquakes with residuals larger than a factor of 3 , the estimated moments do reflect the amplitudes seen in individual seismograms, as discussed in the (E) electronic supplement. It is unclear to us why these moment estimates differ significantly from the magnitude calibration.

\section{Implications for Comparison with Geodetic Observations}

The recalibrated moment scaling obtained in this study has been used by Hawthorne et al. (2016) to investigate the relationship between postseismic and coseismic moments of small earthquakes. They compare the seismic moments with borehole strain observations at nearby strainmeter SJT, operated by the U.S. Geological Survey. To demonstrate the importance of the recalibration, in Figure $8 \mathrm{a}$ we reproduce two of their strain estimates: the coseismic strain, accumulated within $20 \mathrm{~min}$ of the earthquakes, and the total strain, accumulated within 1.5 days. These observed strains are normalized by the predicted coseismic strain computed from the seismic moments, which are assumed to follow the recalibrated scaling $M_{0} \sim 10^{1.1 M}$. In Figure $8 \mathrm{~b}$, we plot a similar result, with the same approach to predicting the coseismic strain, but this time the seismic moments are assumed to follow a moment-magnitude scaling $M_{0} \sim 10^{1.5 M}$.

With the recalibrated scaling, the observed coseismic and total strains are constant multiples of the expected coseismic strain, with no dependence on magnitude. The observed coseismic steps are larger than expected, perhaps because of errors in the absolute moment calibration or uncertainty in the Green's functions for strain (Hawthorne et al., 2016), but overall the constant ratio is consistent with a simple, self-similar behavior of earthquakes, where $M 2$ earthquakes are simply smaller versions of $M 4$ events. With the moment-magnitude scaling used in Figure $8 b$, on the other hand, both the coseismic and total strains increase relative to the expected strains as magnitude decreases. Using this scale could have resulted in an incorrect and complicated interpretation of the strain data. For instance, one might have interpreted the apparently large strain in small earthquakes as the result of large postseismic slip. Such large postseismic slip was proposed to explain the long recurrence intervals of repeating earthquakes (Nadeau and Johnson, 1998; Chen and Lapusta, 2009). However, it does not show up in the first 1.5 days of strain data when proper calibrations are used.

\section{Conclusions}

We estimate the relative source amplitudes of 1600 earthquakes in a $20 \mathrm{~km}$ region near San Juan Bautista, California, and use them to recalibrate the local magnitude scale. We use spectral amplitudes, coupled with an empirical Green's function method, to obtain the moments. Our approach avoids the calculation of path or site effects. The method works well in the San Juan Bautista region. Half of the estimated amplitudes have $90 \%$ bootstrap uncertainties
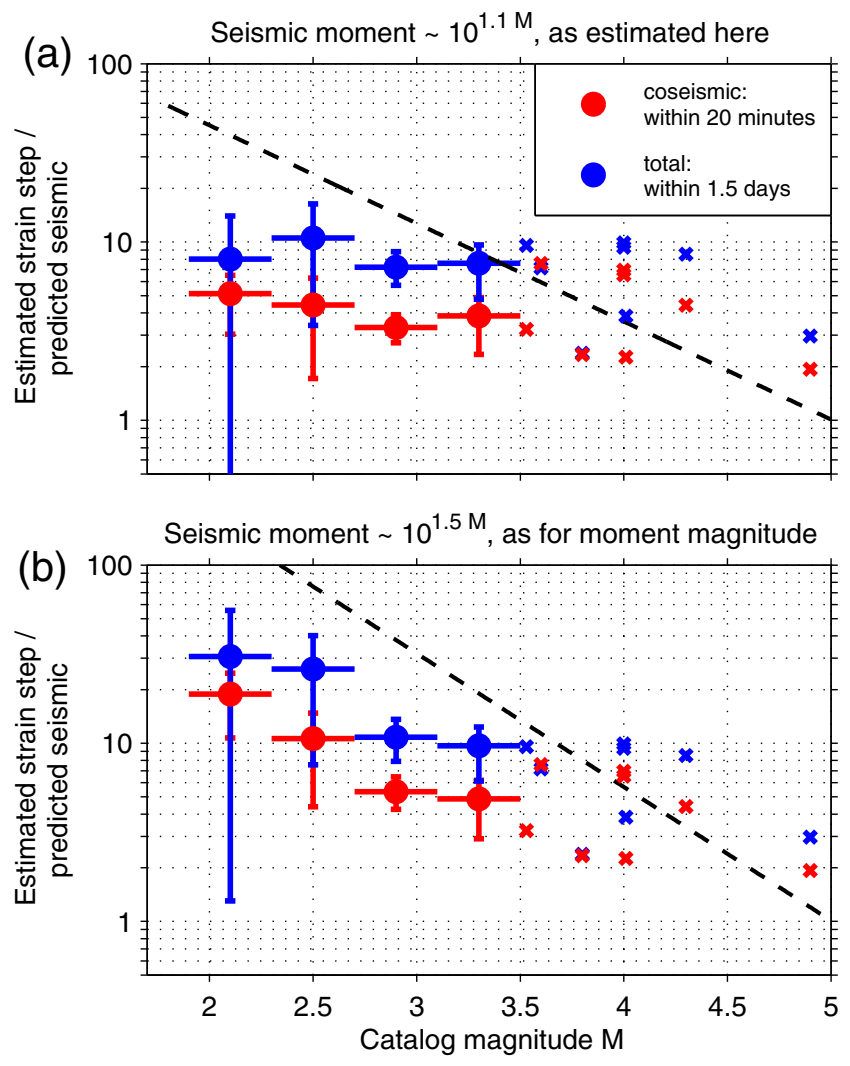

Figure 8. Estimates of strain associated with small earthquakes, relative to the strain expected from seismic moments. (a) Reproduced from Hawthorne et al. (2016). Smaller values indicate the coseismic strain (within 20 min of the earthquakes), whereas larger values indicate the total strain (coseismic plus 1.5 days after the earthquakes). Crosses are shown for individual earthquakes, and circles with error bars are shown for averages within the indicated magnitude ranges. In (a), the predicted coseismic strain is computed with the magnitude scaling obtained here: $M_{0} \sim 10^{1.1 M}$, and the normalized observed strains are roughly constant with magnitude. In (b), the predicted coseismic strain is computed with a moment-magnitude scaling: $M_{0} \sim 10^{1.5 M}$, and the normalized observed strains appear to increase with decreasing magnitude. The black dashed line indicates the slope of the ratio of the total (coseismic plus postseismic) moment to the coseismic moment that would be required to match the recurrence interval scaling seen in repeating earthquakes (Nadeau and Johnson, 1998; Chen and Lapusta, 2009; Hawthorne et al., 2016). The color version of this figure is available only in the electronic edition.

smaller than a factor of 1.3 . The approach is likely helped by the relatively simple fault geometry and the large percentage of on-fault earthquakes.

The estimated moments represent only a subset of the earthquakes. To extrapolate to more events, we re-estimate the scaling between moment and catalog magnitude. This scaling indicates that the moment increases with catalog magnitude $M_{\mathrm{D}}$ as $10^{1.1 M_{\mathrm{D}}}$. Our calibration results are similar to previous calibrations of the local magnitude scale for small earthquakes (Bakun and Lindh, 1977; Archuleta et al., 1982; Bakun, 1984b; Fletcher et al., 1984). The results differ from the $10^{1.5 M}$ scaling expected for moment magnitudes. The obtained scaling, and the method used for moment estimation, 
can be used for analyses requiring accurate moment scalings such as comparisons between seismic and geodetic moments.

\section{Data and Resources}

We used seismic waveform data and the Northern California Seismic Network (NCSN; http://www.ncedc.org/, last accessed May 2015) earthquake catalog, provided by the Northern California Earthquake Data Center (NCEDC) and the Berkeley Seismological Laboratory (10.7932/NCEDC). The strain data were recorded by strainmeter SJT, operated by the U.S. Geological Survey (USGS) and were obtained at http://earthquake.usgs.gov/monitoring/deformation/data/ download/table.php. The fault traces shown in Figure 1 were obtained from the USGS and California Geological Survey fault and fold database, accessed from http:// earthquake.usgs.gov/hazards/qfaults/. All databases were accessed in May 2015.

\section{Acknowledgments}

We thank Grzegorz Kwiatek and two anonymous reviewers for useful comments on the article.

\section{References}

Abercrombie, R. E. (1995). Earthquake locations using single-station deep borehole recordings: Implications for microseismicity on the San Andreas fault in southern California, J. Geophys. Res. 100, no. B12, 24,003-24,014, doi: 10.1029/95JB02396.

Abercrombie, R. E. (1996). The magnitude-frequency distribution of earthquakes recorded with deep seismometers at Cajon Pass, southern California, Tectonophysics 261, nos. 1/3, 1-7, doi: 10.1016/0040-1951(96)00052-2.

Abercrombie, R. E. (2014). Stress drops of repeating earthquakes on the San Andreas fault at Parkfield, Geophys. Res. Lett. 41, no. 24, 8784-8791, doi: 10.1002/2014GL062079.

Aki, K., and P. G. Richards (2002). Quantitative Seismology, Second Ed., University Science Books, Sausalito, California.

Allmann, B. P., and P. M. Shearer (2007). Spatial and temporal stress drop variations in small earthquakes near Parkfield, California, J. Geophys. Res. 112, no. B04305, doi: 10.1029/2006JB004395.

Allmann, B. P., and P. M. Shearer (2009). Global variations of stress drop for moderate to large earthquakes, J. Geophys. Res. 114, no. B01310, doi: 10.1029/2008JB005821.

Archuleta, R. J., E. Cranswick, C. Mueller, and P. Spudich (1982). Source parameters of the 1980 Mammoth Lakes, California, earthquake sequence, $J$. Geophys. Res. 87, no. B6, 4595-4607, doi: 10.1029/JB087iB06p04595.

Bakun, W. H. (1984a). Magnitudes and moments of duration, Bull. Seismol. Soc. Am. 74, no. 6, 2335-2356.

Bakun, W. H. (1984b). Seismic moments, local magnitudes, and codaduration magnitudes for earthquakes in central California, Bull. Seismol. Soc. Am. 74, no. 2, 439-458.

Bakun, W. H., and A. G. Lindh (1977). Local magnitudes, seismic moments, and coda durations for earthquakes near Oroville, California, Bull. Seismol. Soc. Am. 67, no. 3, 615-629.

Baltay, A., S. Ide, G. Prieto, and G. Beroza (2011). Variability in earthquake stress drop and apparent stress, Geophys. Res. Lett. 38, L06303, doi: 10.1029/2011GL046698.

Baltay, A., G. Prieto, and G. C. Beroza (2010). Radiated seismic energy from coda measurements and no scaling in apparent stress with seismic moment, J. Geophys. Res. 115, B08314, doi: 10.1029/2009JB006736.

Bell, J. W., F. Amelung, and C. D. Henry (2012). InSAR analysis of the 2008 Reno-Mogul earthquake swarm: Evidence for westward migration of
Walker Lane style dextral faulting, Geophys. Res. Lett. 39, L18306, doi: 10.1029/2012GL052795.

Ben-Zion, Y., and L. Zhu (2002). Potency-magnitude scaling relations for southern California earthquakes with $1.0<M_{\mathrm{L}}<7.0$, Geophys. J. Int. 148, no. 3, F1-F5, doi: 10.1046/j.1365-246X.2002.01637.x.

Bethmann, F., N. Deichmann, and P. M. Mai (2011). Scaling relations of local magnitude versus moment magnitude for sequences of similar earthquakes in Switzerland, Bull. Seismol. Soc. Am. 101, no. 2, 515-534, doi: 10.1785/0120100179.

Bindi, D., D. Spallarossa, C. Eva, and M. Cattaneo (2005). Local and duration magnitudes in northwestern Italy, and seismic moment versus magnitude relationships, Bull. Seismol. Soc. Am. 95, no. 2, 592-604, doi: $10.1785 / 0120040099$.

Brune, J. N. (1970). Tectonic stress and the spectra of seismic shear waves from earthquakes, J. Geophys. Res. 75, 4997-5009, doi: 10.1029/ JB075i026p04997.

Castello, B., M. Olivieri, and G. Selvaggi (2007). Local and duration magnitude determination for the Italian earthquake catalog, 1981-2002, Bull. Seismol. Soc. Am. 97, no. 1B, 128-139, doi: 10.1785/0120050258.

Chen, T., and N. Lapusta (2009). Scaling of small repeating earthquakes explained by interaction of seismic and aseismic slip in a rate and state fault model, J. Geophys. Res. 114, B01311, doi: 10.1029/2008JB005749.

Chernick, M. R. (2007). When bootstrapping fails along with some remedies for failures, in Bootstrap Methods: A Guide for Practitioners and Researchers, John Wiley \& Sons, Inc, Hoboken, New Jersey, 172-187.

Cleveland, K. M., and C. J. Ammon (2015). Precise relative earthquake magnitudes from cross correlation, Bull. Seismol. Soc. Am. 105, no. 3, 1792-1796, doi: 10.1785/0120140329.

Deichmann, N. (2006). Local magnitude, a moment revisited, Bull. Seismol. Soc. Am. 96, no. 4A, 1267-1277, doi: 10.1785/0120050115.

Dreger, D. S., and D. V. Helmberger (1990). Broadband modeling of local earthquakes, Bull. Seismol. Soc. Am. 80, no. 5, 1162-1179.

Eaton, J. P. (1992). Determination of amplitude and duration magnitudes and site residuals from short-period seismographs in northern California, Bull. Seismol. Soc. Am. 82, no. 2, 533-579.

Edwards, B., B. Allmann, D. Fäh, and J. Clinton (2010). Automatic computation of moment magnitudes for small earthquakes and the scaling of local to moment magnitude, Geophys. J. Int. 183, no. 1, 407-420, doi: 10.1111/j.1365-246X.2010.04743.x.

Fattahi, H., F. Amelung, E. Chaussard, and S. Wdowinski (2015). Coseismic and postseismic deformation due to the 2007 M 5.5 Ghazaband fault earthquake, Balochistan, Pakistan, Geophys. Res. Lett. 42, no. 9, 3305-3312, doi: 10.1002/2015GL063686.

Fletcher, J., J. Boatwright, L. Haar, T. Hanks, and A. McGarr (1984). Source parameters for aftershocks of the Oroville, California, earthquake, Bull. Seismol. Soc. Am. 74, no. 4, 1101-1123.

Gasperini, P., B. Lolli, and G. Vannucci (2013). Empirical calibration of local magnitude data sets versus moment magnitude in Italy, Bull. Seismol. Soc. Am. 103, no. 4, 2227-2246, doi: 10.1785/0120120356.

Ghosh, A., A. V. Newman, A. M. Thomas, and G. T. Farmer (2008). Interface locking along the subduction megathrust from b-value mapping near Nicoya Peninsula, Costa Rica, Geophys. Res. Lett. 35, L01301, doi: 10.1029/2007GL031617.

Hanks, T. C., and D. M. Boore (1984). Moment-magnitude relations in theory and practice, J. Geophys. Res. 89, no. B7, 6229-6235, doi: 10.1029/JB089iB07p06229.

Hanks, T. C., and H. Kanamori (1979). A moment magnitude scale, J. Geophys. Res. 84, 2348-2350, doi: 10.1029/JB084iB05p02348.

Harrington, R. M., G. Kwiatek, and S. C. Moran (2015). Self-similar rupture implied by scaling properties of volcanic earthquakes occurring during the 2004-2008 eruption of Mount St. Helens, Washington, J. Geophys. Res. 120, no. 7, 4966-4982, doi: 10.1002/2014JB011744.

Hawthorne, J. C., M. Simons, and J.-P. Ampuero (2016). Estimates of aseismic slip associated with small earthquakes near San Juan Bautista, CA, J. Geophys. Res. doi: 10.1002/2016JB013120.

Herrmann, R. B. (1975). The use of duration as a measure of seismic moment and magnitude, Bull. Seismol. Soc. Am. 65, no. 4, 899-913. 
Hough, S. E. (1997). Empirical Green's function analysis: Taking the next step, J. Geophys. Res. 102, 5369-5384, doi: 10.1029/96JB03488.

Ide, S., G. C. Beroza, S. G. Prejean, and W. L. Ellsworth (2003). Apparent break in earthquake scaling due to path and site effects on deep borehole recordings, J. Geophys. Res. 108, no. B5, 2271, doi: 10.1029/ $2001 \mathrm{JB} 001617$.

Ide, S., M. Matsubara, and K. Obara (2004). Exploitation of high-sampling Hi-net data to study seismic energy scaling: The aftershocks of the 2000 Western Tottori, Japan, earthquake, Earth Planets Space 56, no. 9, 859-871, doi: 10.1186/BF03352533.

Imanishi, K., and W. L. Ellsworth (2006). Source scaling relationships of microearthquakes at Parkfield, CA, determined using the SAFOD pilot jole seismic array, in Earthquakes: Radiated Energy and the Physics of Faulting, R. Abercrombie, A. McGarr, G. D. Toro, and H. Kanamori (Editors), American Geophysical Union, Washington, D.C., 81-90, doi: 10.1029/170GM10.

Imanishi, K., W. L. Ellsworth, and S. G. Prejean (2004). Earthquake source parameters determined by the SAFOD Pilot Hole seismic array, Geophys. Res. Lett. 31, L12S09, doi: 10.1029/2004GL019420.

Kwiatek, G., P. Martínez-Garzón, G. Dresen, M. Bohnhoff, H. Sone, and C. Hartline (2015). Effects of long-term fluid injection on induced seismicity parameters and maximum magnitude in northwestern part of the Geysers geothermal field, J. Geophys. Res. 120, no. 10, 7085-7101, doi: $10.1002 / 2015 J B 012362$.

Kwiatek, G., K. Plenkers, G. Dresen, and J. R. Group (2011). Source parameters of picoseismicity recorded at Mponeng deep gold mine, South Africa: Implications for scaling relations, Bull. Seismol. Soc. Am. 101, no. 6, 2592-2608, doi: 10.1785/0120110094.

Lee, W. H. K., R. Bennett, and K. Meagher (1972). A method of estimating magnitude of local earthquakes from signal duration, USGS Numbered Series 72-223, U.S. Geological Survey.

Madariaga, R. (1976). Dynamics of an expanding circular fault, Bull. Seismol. Soc. Am. 66, no. 3, 639-666.

Madariaga, R (2007). Seismic source theory, in Treatise on Geophysics, H. Kanamori and G. Schubert (Editors), Vol. 4, Earthquake Seismology, Elsevier, Amsterdam, The Netherlands, 6054.

Michaelson, C. A. (1990). Coda duration magnitudes in central California: An empirical approach, Bull. Seismol. Soc. Am. 80, no. 5, 1190-1204.

Mori, J., and A. Frankel (1990). Source parameters for small events associated with the 1986 North Palm Springs, California, earthquake determined using empirical Green functions, Bull. Seismol. Soc. Am. 80, no. $2,278-295$.

Mueller, C. S. (1985). Source pulse enhancement by deconvolution of an empirical Green's function, Geophys. Res. Lett. 12, no. 1, 33-36, doi: 10.1029/GL012i001p00033.

Nadeau, R. M., and L. R. Johnson (1998). Seismological studies at Parkfield VI: Moment release rates and estimates of source parameters for small repeating earthquakes, Bull. Seismol. Soc. Am. 88, no. 3, 790-814.

Oye, V., H. Bungum, and M. Roth (2005). Source parameters and scaling relations for mining-related seismicity within the Pyhäsalmi ore mine, Finland, Bull. Seismol. Soc. Am. 95, no. 3, 1011-1026, doi: 10.1785/ 0120040170.

Percival, D. B., and A. T. Walden (1993). Spectral Analysis for Physical Applications, First Ed., Cambridge University Press, Cambridge, United Kingdom.

Prejean, S. G., and W. L. Ellsworth (2001). Observations of earthquake source parameters at $2 \mathrm{~km}$ depth in the Long Valley caldera, eastern California, Bull. Seismol. Soc. Am. 91, no. 2, 165-177, doi: 10.1785/ 0120000079.

Prieto, G. A., P. M. Shearer, F. L. Vernon, and D. Kilb (2004). Earthquake source scaling and self-similarity estimation from stacking $P$ and $S$ spectra, J. Geophys. Res. 109, B08310, doi: 10.1029/2004JB003084.

Ross, Z. E., Y. Ben-Zion, M. C. White, and F. L. Vernon (2016). Analysis of earthquake body wave spectra for potency and magnitude values: Implications for magnitude scaling relations, Geophys. J. Int. 207, no. 2, 1158-1164, doi: 10.1093/gji/ggw327.
Rubinstein, J. L., and W. L. Ellsworth (2010). Precise estimation of repeating earthquake moment: Example from Parkfield, California, Bull. Seismol. Soc. Am. 100, no. 5A, 1952-1961, doi: 10.1785/0120100007.

Schaff, D. P., and P. G. Richards (2014). Improvements in magnitude precision, using the statistics of relative amplitudes measured by cross correlation, Geophys. J. Int. 197, no. 1, 335-350, doi: 10.1093/gji/ggt433.

Shearer, P. M., G. A. Prieto, and E. Hauksson (2006). Comprehensive analysis of earthquake source spectra in southern California, J. Geophys. Res. 111, B06303, doi: 10.1029/2005JB003979.

Taira, T., R. Bürgmann, R. M. Nadeau, and D. S. Dreger (2014). Variability of fault slip behavior along the San Andreas fault in the San Juan Bautista region, J. Geophys. Res. 119, no. 12, 8827-8844, doi: 10.1002/ 2014JB011427.

Templeton, D. C., R. M. Nadeau, and R. Bürgmann (2008). Behavior of repeating earthquake sequences in central California and the implications for subsurface fault creep, Bull. Seismol. Soc. Am. 98, no. 1, 5265, doi: 10.1785/0120070026.

Uchide, T., P. M. Shearer, and K. Imanishi (2014), Stress drop variations among small earthquakes before the 2011 Tohoku-oki, Japan, earthquake and implications for the main shock, J. Geophys. Res. 119, no. 9, 7164-7174, doi: 10.1002/2014JB010943.

Uhrhammer, R. A., M. Hellweg, K. Hutton, P. Lombard, A. W. Walters, E. Hauksson, and D. Oppenheimer (2011). California Integrated Seismic Network (CISN) local magnitude determination in California and vicinity, Bull. Seismol. Soc. Am. 101, no. 6, 2685-2693, doi: 10.1785/ 0120100106.

Uhrhammer, R. A., S. J. Loper, and B. Romanowicz (1996). Determination of local magnitude using BDSN broadband records, Bull. Seismol. Soc. Am. 86, no. 5, 1314-1330.

Velasco, A. A., C. J. Ammon, and T. Lay (1994). Empirical green function deconvolution of broadband surface waves: Rupture directivity of the 1992 Landers, California $\left(M_{\mathrm{w}}=7.3\right)$, earthquake, Bull. Seismol. Soc. Am. 84, no. 3, 735-750.

Waldhauser, F. (2009). Near-real-time double-difference event location using long-term seismic archives, with application to northern California, Bull. Seismol. Soc. Am. 99, no. 5, 2736-2748, doi: 10.1785/0120080294.

Werner, M. J., and D. Sornette (2008). Magnitude uncertainties impact seismic rate estimates, forecasts, and predictability experiments, $J$. Geophys. Res. 113, B08302, doi: 10.1029/2007JB005427.

Wiemer, S., M. Gerstenberger, and E. Hauksson (2002). Properties of the aftershock sequence of the $1999 M_{\mathrm{w}} 7.1$ Hector Mine earthquake: Implications for aftershock hazard, Bull. Seismol. Soc. Am. 92, no. 4, 1227-1240, doi: 10.1785/0120000914.

Wyss, M., C. G. Sammis, R. M. Nadeau, and S. Wiemer (2004). Fractal dimension and $b$-value on creeping and locked patches of the San Andreas fault near Parkfield, California, Bull. Seismol. Soc. Am. 94, no. 2, 410-421, doi: 10.1785/0120030054

Yamada, T., J. J. Mori, S. Ide, R. E. Abercrombie, H. Kawakata, M. Nakatani, Y. Iio, and H. Ogasawara (2007). Stress drops and radiated seismic energies of microearthquakes in a South African gold mine, J. Geophys. Res. 112, B03305, doi: 10.1029/2006JB004553.

Zhu, L., and D. V. Helmberger (1996). Advancement in source estimation techniques using broadband regional seismograms, Bull. Seismol. Soc. Am. 86, no. 5, 1634-1641.

Appendix

\section{Data Choice and Spectral Estimation}

To estimate the relative seismic moments of local earthquakes, we use data and $P$-wave picks from the Northern California Seismic Network (NCSN) catalog between 1988 

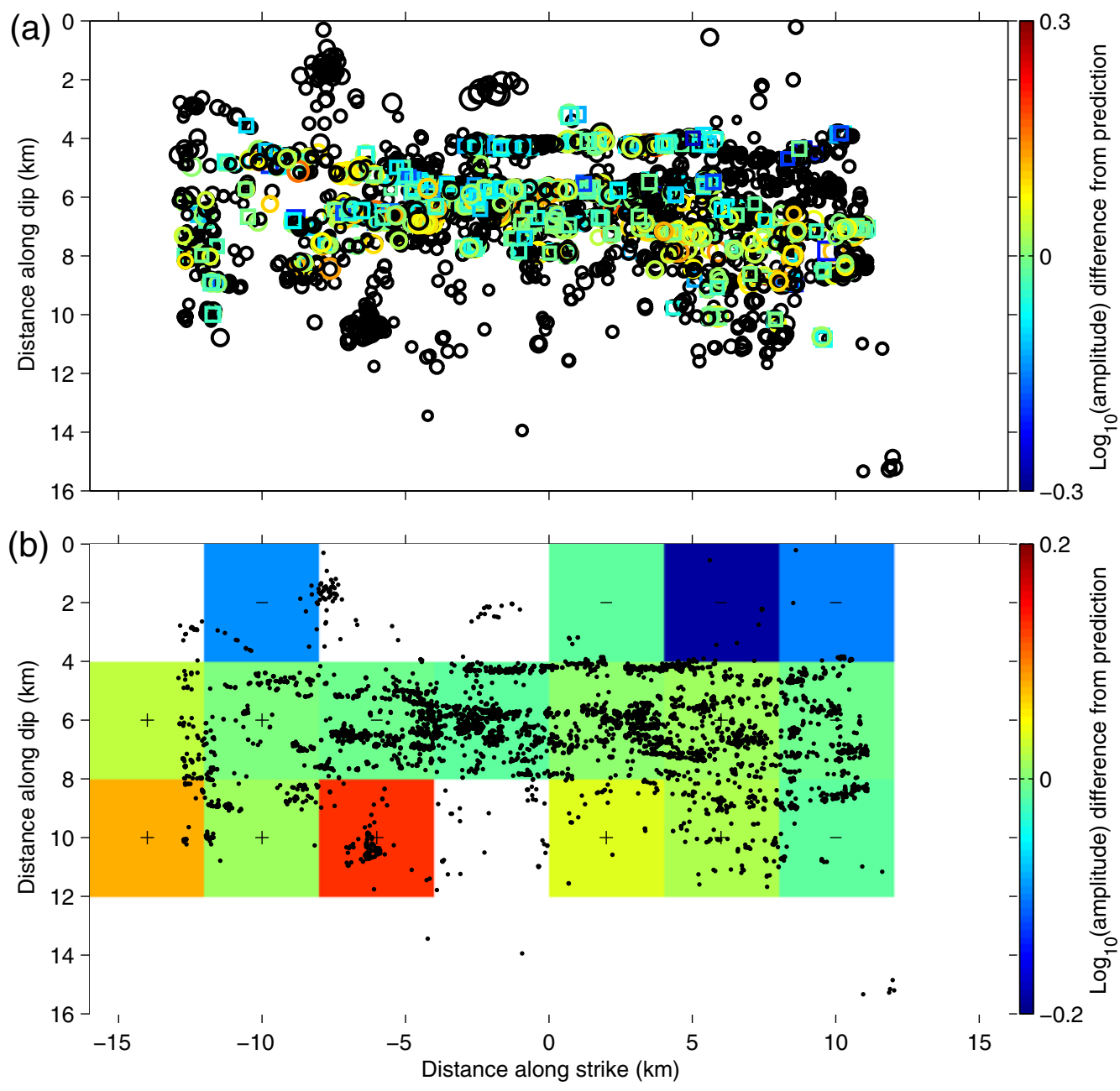

Figure A1. (a) Earthquakes projected along the fault. Shading indicates their misfit from the best-fitting magnitude scaling. Circles are plotted for earthquakes with positive misfit, and squares are plotted for earthquakes with negative misfit. (b) Average misfits within $4 \mathrm{~km}$ squares along the fault, with plus signs in boxes with positive misfits and minus signs in boxes with negative misfits. The spatial variation in the misfit is weak, and within the range expected from the bootstrapped errors. The color version of this figure is available only in the electronic edition.

and 2014. We initially consider seismograms associated with about 5000 earthquakes that occurred within a $20 \mathrm{~km}$ region along the fault, between $238^{\circ} 20^{\prime} \mathrm{E}$ and $238^{\circ} 33^{\prime} \mathrm{E}$ (see Fig. 1).

Some of the seismograms are clipped. The clipped seismograms can be identified automatically because they include a large number of values near their upper and lower limits. We check four intervals after the $P$-wave arrival for clipping: $0-0.5 \mathrm{~s}, 0-1 \mathrm{~s}, 1-2 \mathrm{~s}$, and $0-5 \mathrm{~s}$. A record is excluded if $25 \%$ of the values in an interval differ from the median by more than $70 \%$ of the maximum difference.

For records that appear free of clipping, we compute the spectra of the velocity seismograms and check the signal-tonoise ratio (SNR). We extract $4 \mathrm{~s}$ windows starting at the pick time. Spectra are computed using a multitaper approach (e.g., Percival and Walden, 1993). The tapers are concentrated at frequencies smaller than $0.5 \mathrm{~Hz}$, so that tapering smooths the spectra at frequency spacings smaller than $0.5 \mathrm{~Hz}$.
The spectra of three earlier intervals are taken as estimates of the noise. These intervals are 13-9 s, 9-5 s, and $5-1 \mathrm{~s}$ before the $P$ arrival. A record is discarded if the SNR is smaller than 3 in any of the $1-5,5-10,10-15$, or $15-20 \mathrm{~Hz}$ bands.

For each of the acceptable spectra, we convert the velocity records to displacement by dividing by frequency, and we correct the spectra for the instrumental response. We take the logarithm of the spectra and compute the average logspectral amplitude in the $2-4 \mathrm{~Hz}$ band.

\section{Lack of Spatial Bias}

When we estimate the relative amplitudes of earthquakes $1 \mathrm{~km}$ apart, we assume that the amplitudes of their Green's functions are the same. This assumption may be somewhat wrong, but it would be especially problematic if 
it were wrong systematically. For instance, what if there were more stations to the southeast? More southeasterly earthquakes would then have slightly shorter paths, and thus higher amplitudes, which we might map into larger moments in the southeast.

We see no evidence for such systematic biases. When we further restrict the data by requiring smaller distances between earthquakes or reduced relative travel times, the moments stay the same within error. They also appear the same when we try to avoid a strong azimuthal bias, for instance, when we require that a northwestern station is used each time a southeastern station is used.

Another way to look for systematic biases in our approach is to examine spatial patterns in the estimated earthquake moments, relative to the best-fitting scaling between moment and catalog magnitude. The shading of the earthquakes in Figure A1a indicates the difference between the magnitude prediction and the estimated moments. Figure A1b shows the average difference within $4 \mathrm{~km}$ blocks. Most of the blocks show average differences of less than $10 \%$, and the variation is within the range expected from the bootstrap errors. This consistency suggests that there is no spatial bias in our moment estimates, at least relative to the catalog magnitudes.

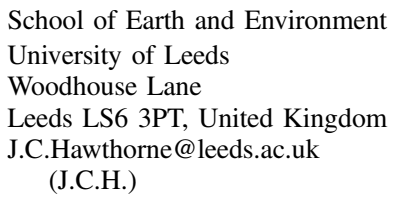

Seismological Laboratory

Division of Geological and Planetary Sciences

MS 252-21, 1200 East California Boulevard

Pasadena, California 91125

ampuero@gps.caltech.edu

simons@caltech.edu

(J.-P.A., M.S.)

Manuscript received 9 May 2016;

Published Online 20 December 2016 